ARTICLES

\title{
Facebook as a tool for respondent tracing
}

Sid Schneider', Amelia Burke-Garcia', Gail Thomas

${ }^{1}$ Westat 1600 Research Boulevard Rockville MD 20850

Keywords: longitudinal surveys, social network web sites

https://doi.org/10.29115/SP-2015-0003

\section{Survey Practice}

Vol. 8, Issue 1, 2015

\begin{abstract}
In longitudinal research projects, respondents' contact information such as address, telephone, and email can become out-of-date. Some researchers have searched Facebook for these unreachable respondents, with the hope of sending them a private message that asks them to provide the needed follow-up data. Published reports of research that used Facebook that way raise several questions: When should researchers conclude that a Facebook user is actually the respondent they are seeking? How should researchers word their message? To what extent is respondent tracing through Facebook likely to reduce nonresponse bias? Is communication using Facebook sufficiently confidential? This paper discusses these questions and presents Westat's own use of Facebook to trace respondents in a longitudinal evaluation of an intervention for youth in foster care. The paper discusses the implications of ourwork for future research practice.
\end{abstract}

\section{Introduction}

Over 160 million people in the United States have Facebook accounts (Internet World Stats 2012). With that high level of coverage, Facebook might be ready to take a more significant role in survey research. In particular, Facebook might serve as a tool for researchers who need to track down specific respondents.

Researchers may have names, addresses, telephone numbers, and email addresses for their respondents but still have difficulty finding them for followup data collection (Alderman et al. 2001). The main reason for this problem is that the respondents change their addresses, telephone numbers, and email addresses without informing the researchers (Calderwood 2012).

By contrast, Facebook users have profiles (also called "timelines") which never change, even when they move or switch to a new email provider. Facebook would therefore appear to be exactly what a researcher needs: a medium for contacting respondents that does not go out of date.

Facebook would seem to be an especially promising way to reach young respondents. Census Bureau (2012) data suggest that young people are particularly likely to move; 22 percent of 18 to 24 year olds and 21 percent of 25 to 34 year olds moved from 2011 to 2012, far more than any other age groups. It is therefore not surprising that young respondents were disproportionately likely to become unreachable in several longitudinal studies (Littman et al. 2010; Seed, Juarez, and Alnatour 2009; A. F. Young, Powers, and Bell 2006). 
At the same time, young people are especially likely to use social networking websites like Facebook (Duggan and Brenner 2013). Even very vulnerable young people tend to use the websites; in one study of homeless youth, over three quarters were active users (S. D. Young and Rice 2011).

Eight research teams have published articles describing their experiences using Facebook to trace respondents. Berry and Bass (2012) administered surveys on religiosity, substance abuse, and anxiety to young people over the course of a school year. Bolanos et al. (2012) administered a survey twice to amphetamine abusers over the course of 8 years. Daniel, Brooks, and Waterbor (2011) administered a follow-up survey to students who had participated in a program to promote cancer research as a career. Jones et al. (2012) administered a survey about physical activity to girls in eighth grade and then again three years later. Mychasiuk and Benzies (2012) collected data three times over 5 years from children and their parents who participated in a pre-school program for atrisk families. Nwadiuko et al. (2011) administered questionnaires about abuse and neglect to children every two years. Perkins, Granger, and Saleska (2009) conducted a series of at-home interviews about health with young people from 1994 to 2008. Rhodes and Marks (2011) collected data about finances from new parents and again when their children turned 3. The experiences of these research teams highlight the issues that researchers may encounter when using Facebook to trace hard-to-reach respondents.

How can researchers tell whether or not a Facebook user is the respondent they are seeking? Some of the research teams conducted searches on Facebook but received ambiguous results. Sometimes the researchers found Facebook users who had posted information about themselves that only partially matched the respondents. Sometimes Facebook users had multiple profiles, in violation of Facebook's terms of service, and the information posted on the profiles was inconsistent. Sometimes Facebook users who had the same names as respondents being sought posted scant information about themselves. The research teams therefore had to establish criteria about which Facebook users should be considered a "match" with a respondent.

\section{How should researchers initiate contact with Facebook users who} appear to be the respondents? The research teams in the eight published reports sent out private messages to the Facebook users who they thought might be the respondents. They worded the messages carefully. Recipients had to quickly see that the messages were legitimate, not spam. The messages had to jog each respondent's memory about the research. The messages had to be brief, since many recipients would read them on the small screen of a smartphone. Also, the messages had to motivate the recipients to respond indicating whether or not they were in fact the respondents. Nwadiuko et al. (2011) went further, asking the recipients of the messages to prove that they were the survey respondents by sending the first name of their parents or guardians. 
What should appear in the "From" line? Some of the 8 researcher teams sent private messages that had the name of the research project in the "From" line, even though Facebook's terms of service require that only the names of people can appear in the "From" line.

Can using Facebook for respondent tracing reduce nonresponse bias? The researchers in the eight published reports found relatively few respondents by searching on Facebook. For example, using traditional tracing methods like the telephone, Jones et al. (2012) could not find 175 of the 730 respondents in their longitudinal survey of physical activity. They found 78 of those 175 on Facebook, and 43 of those agreed to provide data. That number is small, but the respondents who were located on Facebook were significantly different from the respondents who were found using traditional methods as to their levels of physical activity. Similarly, Rhodes and Marks (2011) could find only 294 of 919 unreachable respondents on Facebook. However, the respondents that they found on Facebook were significantly different from other respondents as to education, race, and household income.

Does using Facebook for respondent tracing compromise privacy and confidentiality? Private messages sent within Facebook are not publicly accessible. Even so, they reside on servers over which researchers have no control. The fate of the messages is purely in Facebook's hands.

Moreover, a researcher might unintentionally send a private message to someone who is not the respondent. That situation is arguably equivalent to telling the recipient of the message that someone with a similar name was a research participant.

\section{Our Experience}

Recently, researchers at Westat used Facebook to trace adolescents in a randomized, controlled evaluation of an intervention for youth in foster care. Ranging in age from 13 to 17 at the time of randomization, the 366 foster youth were interviewed twice: at 12 months and 24 months after referral to an intervention condition. The interviews were conducted in person (or telephone when necessary) and covered a range of topics, including education, friends, self-efficacy, drug use, and sexual activity.

The evaluation sample included a relatively large number of youth who had aged out of foster care and were difficult to find for the follow-up interviews, especially at 24 months. Adding to this problem, it was not uncommon for the foster youth to run away as they neared their 18th birthday. When social workers could not provide current contact information, and alternate contact information was not available or exhausted, we put the names of youth and known friends through a number of resources, including Lexis-Nexis public data, Instant Checkmate, and Intelius. We also searched for the young people on websites that document arrests or imprisonment, such as inmate search engines. 
Once those resources were exhausted, we entered the respondent's name in the search feature on Facebook. If our search yielded results, we examined individual profiles for clues to the Facebook users' identities. If the privacy settings permitted, we looked for each account owner's birth date, high school, and physical location. If we thought that an account probably belonged to the respondent, we sent a private message using the message feature. (During this evaluation, Facebook charged one dollar to send a message to a non-friend. At this writing, Facebook continues to charge one dollar to send a message to the recipient's inbox but also offers a free message option that goes to an "Other" folder, where the message may remain unnoticed.)

Our messages varied, depending on our history with the youth. For example, a message sent to a youth we had interviewed previously would be, "Hi, [NAME]. I work on the [PROJECT NAME]. We've been trying to locate you for the second (and last) interview. Are you still in the area? We'd like to meet with you again. This second interview is shorter $;$ and we will pay you $\$ 30$. Are you interested? Thanks in advance for reading my message! Hope you're having a good summer and staying cool! Kind regards, Gail.”

The "From" line of the message contained the researcher's name. In case recipients of the message might check the researcher's Facebook profile, the profile contained neither political content nor overtly personal information.

We used Facebook to search for 33 respondents, all for the 24-month followup. We eventually heard from 21 of those respondents, not necessarily via a return Facebook message. Of those 21, one refused to be interviewed, and we interviewed 20. Possibly, the Facebook message motivated some young people to reply to telephone or email messages that they had been ignoring.

An additional three recipients of our private messages replied by saying that they were not the people whom we were trying to reach. None of those replies seemed hostile. We replied with an apology in a private message. We received no messages expressing any objection to our data collection efforts using Facebook. Of all the 366 foster youth in the sample, we completed 24-month follow-up interviews with 283 youth.

\section{Conclusions}

As Facebook usage continues to expand, researchers will continue to repurpose it as a survey tool. For example, for the National Youth in Transition Database (NYTD), state child welfare agencies must find and collect data from adolescents who have left foster care. A response rate of 60 percent is required (Children's Bureau 2012), but the contact information for many of the adolescents may have become outdated. Conceivably, Facebook might offer a way for researchers to locate their respondents in NYTD and similar data collection efforts. Ideally, in future longitudinal research studies, researchers will collect the URLs of their respondents' Facebook profiles while collecting all other contact data, such as the respondents' addresses and telephone 
numbers. In addition, the project consent forms could explicitly mention the possibility of being contacted via Facebook. When researchers use Facebook for respondent tracing, they face several issues that survey researchers do not usually face, such as when they should conclude that a particular Facebook user is probably the respondent whom they need to reach, how to word the private message to that Facebook user, and what should appear in the "From" line, all while respecting Facebook's terms of service and research principles for privacy, confidentiality, and informed consent. 


\section{REFERENCES}

Alderman, H., J.R. Behrman, H.-P. Kohler, J.A. Maluccio, and S.C. Watkins. 2001. "Attrition in Longitudinal Household Survey Data.” Demographic Research 5: 79-124.

Berry, D.M., and C.P. Bass. 2012. "Successfully Recruiting, Surveying, and Retaining College Students: A Description of Methods for the Risk, Religiosity, and Emerging Adulthood Study.” Research in Nursing 60 Health 35 (6): 659-70.

Bolanos, F., D. Herbeck, D. Christou, K. Lovinger, A. Pham, A. Raihan, L. Rodriguez, P. Sheaff, and M.L. Brecht. 2012. "Using Facebook to Maximize Follow-up Response Rates in a Longitudinal Study of Adults Who Use Methamphetamine." Substance Abuse: Research and Treatment 6: 1-11.

Calderwood, L. 2012. “Tracking Sample Members in Longitudinal Studies.” Survey Practice 5 (4). http://www.surveypractice.org/index.php/SurveyPractice/article/view/34/html.

Census Bureau. 2012. "Geographical Mobility/Migration.” 2012. http://www.census.gov/hhes/ migration/data/cps/cps2012.html.

Children’s Bureau. 2012. "About NYTD.” 2012. http://www.acf.hhs.gov/programs/cb/resource/ about-nytd?page=all.

Daniel, C.L., C.M. Brooks, and J.W. Waterbor. 2011. "Approaches for Longitudinally Tracking Graduates of NCI-Funded Short-Term Cancer Research Training Programs.” Journal of Cancer Education 26 (1): 58-63.

Duggan, M., and J. Brenner. 2013. “The Demographics of Social Media Users - 2012.” Pew Internet and American Life Project Report. http://www.pewinternet.org/Reports/2013/Social-mediausers.aspx.

Internet World Stats. 2012. "Internet Users in the Americas.” 2012. http://www.internetworldstats.com/stats2.htm.

Jones, L., B.I. Saksvig, M. Grieser, and D.R. Young. 2012. "Recruiting Adolescent Girls into a Followup Study: Benefits of Using a Social Networking Website." Contemporary Clinical Trials 33 (2): $268-72$.

Littman, A.J., E.J. Boyko, I.G. Jacobson, J. Horton, G.D. Gackstetter, B. Smith, T. Hooper, T.S. Wells, P.J. Amoroso, and T.C. Smith. 2010. "Assessing Nonresponse Bias at Follow-up in a Large Prospective Cohort of Relatively Young and Mobile Military Service Members." BMC Medical Research Methodology 10: 99-109. http://www.biomedcentral.com/1471-2288/10/99.

Mychasiuk, R., and K. Benzies. 2012. "Facebook: An Effective Tool for Participant Retention in Longitudinal Research." Child: Care, Health E' Development 38 (5): 753-56.

Nwadiuko, J., P. Isbell, A.J. Zolotor, J. Hussey, and J.B. Kotch. 2011. "Using Social Networking Sites in Subject Tracing.” Field Methods 23 (1): 77-85.

Perkins, J., R. Granger, and E. Saleska. 2009. "Data Security Considerations When Using Social Networking Websites for Locating and Contacting Sample Members.” In International Field Directors and Technologies Conference. Delray Beach, FL.

Rhodes, B.B., and E.L. Marks. 2011. "Using Facebook to Locate Sample Members." Survey Practice 4 (5). http://www.surveypractice.org/index.php/SurveyPractice/article/view/83.

Seed, M., M. Juarez, and R. Alnatour. 2009. "Improving Recruitment and Retention Rates in Preventive Longitudinal Research with Adolescent Mothers." Journal of Child and Adolescent Psychiatric Nursing 22 (3): 150-53.

Young, A.F., J.R. Powers, and S.L. Bell. 2006. "Attrition in Longitudinal Studies: Who Do You Lose?" Australian and New Zealand Journal of Public Health 30 (4): 353-61. 
Young, S.D., and E. Rice. 2011. "Online Social Networking Technologies, HIV Knowledge, and Sexual Risk and Testing Behaviors among Homeless Youth.” AIDS Behavior 15 (2): 253-60. 